4 nordon 



\section{Examining the desirability of a Northern Dimension Partnership on Culture}

TemaNord 2010:542 
Examining the desirability of a Northern Dimension Partnership on Culture

TemaNord 2010:542

(C) Nordic Council of Ministers, Copenhagen 2010

ISBN 978-92-893-2061-0

This publication is available as Print on Demand (PoD) and can be ordered on

www.norden.org/order. Other Nordic publications are available at www.norden.org/en/publications.

Nordic Council of Ministers

Store Strandstræde 18

DK-1255 Copenhagen K

Phone (+45) 33960200

Fax (+45) 33960202

www.norden.org

\author{
Nordic Council \\ Store Strandstræde 18 \\ DK-1255 Copenhagen K \\ Phone (+45) 33960400 \\ Fax (+45) 33111870
}

\section{Nordic co-operation}

Nordic co-operation is one of the world's most extensive forms of regional collaboration, involving Denmark, Finland, Iceland, Norway, Sweden, and three autonomous areas: the Faroe Islands, Greenland, and Åland.

Nordic co-operation has firm traditions in politics, the economy, and culture. It plays an important role in European and international collaboration, and aims at creating a strong Nordic community in $\varepsilon$ strong Europe.

Nordic co-operation seeks to safeguard Nordic and regional interests and principles in the global community. Common Nordic values help the region solidify its position as one of the world's most innovative and competitive. 


\section{Content}

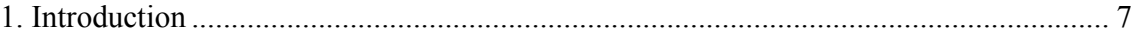

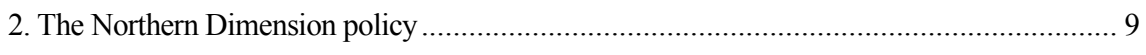

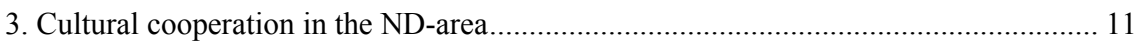

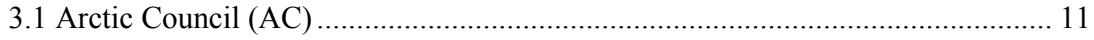

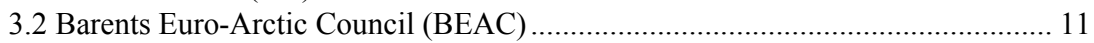

3.3 Council of the Baltic Sea States (CBSS) …….................................................. 12

3.4 Nordic Council of Ministers (NCM) ................................................................ 12

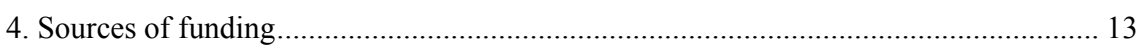

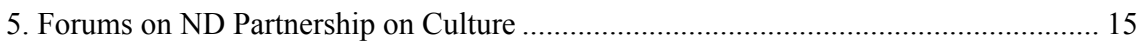

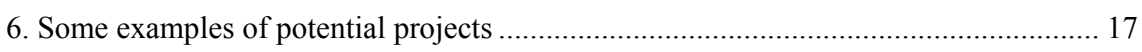

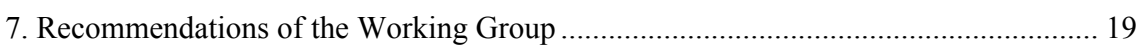

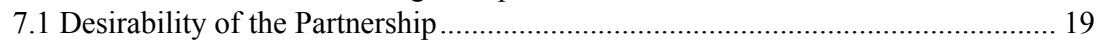

7.2 Objectives of the Partnership........................................................................... 19

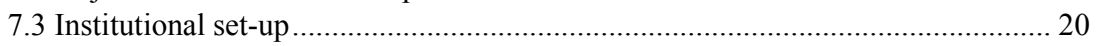

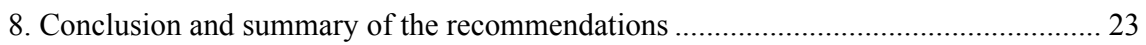

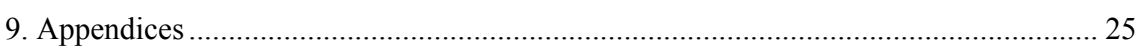

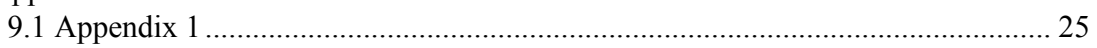

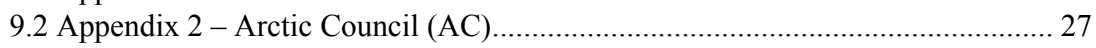

9.3 Appendix 3 - Barents Euro-Arctic Council (BEAC) (www.beac.st) ................... 29

9.4 Appendix 4 - Council of the Baltic Sea States (CBSS) (www.cbss.org) .............. 31

9.5 Appendix 5 - Nordic Council of Ministers www.norden.org............................... 32

9.6 Appendix 6 - A mapping of funding channels and cultural projects

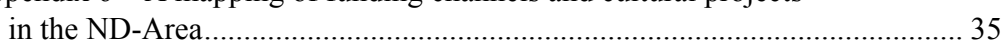

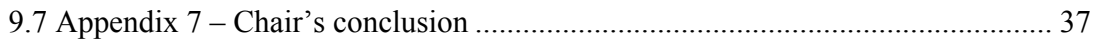

9.8 Appendix 8 - Draft version of two possible projects provided by the consultant ................................................................................... 39 



\section{Introduction}

Holding the Presidency of the Nordic Council of Ministers in 2007, Finland proposed that an assessment be made of the desirability to establish a Northern Dimension Partnership on Culture. A Nordic Policy Group was set up to elaborate the initiative. A report on Why establishing a Northern Dimension Partnership on Culture is desirable was presented to the Northern Dimension Steering Group in September 2008.

Meeting in Riga on 16-17 October 2008, the Ministers of Culture of the Baltic Sea States decided "to support the initiative of the Nordic Council of Ministers to examine, in the Northern Dimension, the creation of a possible Northern Dimension Cultural Partnership".

In their joint statement at the Northern Dimension Ministerial meeting in Saint-Petersburg on October $28^{\text {th }}, 2008$, the Ministers emphasized the considerable potential for cultural cooperation in the area of the Northern Dimension. They appreciated the contribution by the Nordic Council of Ministers into the ongoing discussion on perspectives of such cooperation in the ND framework including the possibility to create a Partnership. They instructed the ND Steering Group to set up an ad-hoc expert group to examine the issue and to assess the feasibility of such a Partnership.

An ad-hoc expert group was set up by the ND Steering Group at a meeting in Oslo on 5 March 2009. ${ }^{1}$ The expert group has held five meetings, on 6 March in Oslo, on 6 April in Copenhagen, on 25 May in Stockholm, on 7 July in Reykjavik, and on 31 August in Copenhagen.

${ }^{1}$ See appendix 1 for the Terms of Reference of the ad-hoc Expert Group 



\section{The Northern Dimension policy}

Following the adoption of a Political Declaration and a Policy Framework Document at the Northern Dimension Summit in November 2006, the Northern Dimension was transformed into a genuinely common policy between the European Union, Iceland, Norway and the Russian Federation. The Northern Dimension forms a regional expression of the Four Common Spaces between the EU and Russia with the participation of Norway and Iceland when appropriate. The Northern Dimension offers a functioning platform for mutually beneficial cooperation across the region to address common challenges.

The Northern Dimension spans a vast geographic area covering the northern EU Member States, Norway, Iceland, and North West Russia, the Baltic Sea region, the Barents region and the Arctic. USA and Canada are observers and the policy encourages expert level cooperation with Belarus. The Northern Dimension covers a range of cooperation sectors and it contributes in increased coordination and synergy between various actors in the region.

The four Regional Councils in the North, the Council of the Baltic Sea States (CBSS), the Barents Euro-Arctic Council (BEAC), the Arctic Council (AC) and the Nordic Council of Ministers (NCM) are recognised in the ND Policy Framework Document as "participants" to the ND policy.

The Political Declaration also expresses a willingness to continue and further develop cooperation within the two existing ND Partnerships, the Environmental Partnership and the Partnership in Public Health and Social Well-being, and to examine possibilities to apply the partnership model to other sectors. The Northern Dimension Ministerial meeting in October 2008 decided to establish a Partnership on Transport and Logistics and a Memorandum of Understanding on the modalities of its establishment is about to be concluded.

One of the priority sectors of the Northern Dimension is research, education and culture, including i.e. "links between cultural and economic life, visibility of regional and local cultural identity and heritage". Culture is also an integral element of the Four Common Spaces and their respective Roadmaps agreed between the European Union and Russia. The Fourth Common Space on Research and Education, including Cultural Aspects i.e. envisages the promotion of a structured approach to cultural cooperation and the development of cooperation between the cultural industries.

Over and above the cooperation in the ND context discussions are also underway with regard to drafting an EU-Russia Culture Action Plan. 



\section{Cultural cooperation in the ND-area}

Both the Regional Councils and the individual Governments in the Northern Dimension area cooperate and take part in and/or finance a multitude of multilateral and bilateral projects and programmes in the cultural sphere. In order to obtain more information on their existing and planned activities in the field of culture a letter was sent to the Chairs and Secretariats of the Regional Councils on 25 June 2009. Their replies, slightly edited, are annexed to this report.

The replies clearly demonstrate a vast diversity of cultural activities implemented by the Regional Councils in their respective geographic regions. Since all four councils are participants to the ND policy and since the ND provides a valuable framework for discussion and cooperation between the councils the NDPC could play an instrumental role also in this regard.

In addition to the multilateral cooperation there are also a vast variety of bilateral actions and projects which can not all be listed in this report. The NDPC could also play an important role in seeking further synergies between these.

\subsection{Arctic Council (AC) $)^{2}$}

Fostering measures to address the challenges in Arctic communities is a major priority of the $\mathrm{AC}$ including i.e. the urgent need for action to support Arctic cultures and reduce the loss of Arctic indigenous languages. The Sustainable Development Working Group of the AC has conducted a wide range of projects and activities that touch upon the cultural dimensions of the circumpolar North, including languages, the economy of the North, reindeer husbandry and living conditions in the Arctic.

\subsection{Barents Euro-Arctic Council (BEAC) ${ }^{3}$}

Cultural cooperation has been an integral part of the Barents cooperation since the founding of BEAC in 1993. In 2007, the BEAC and the Barents Regional Council (BRC) formed a Joint Working Group on Culture. A

\footnotetext{
${ }^{2}$ See appendix 2

${ }^{3}$ See appendix 3
} 
three-year programme, "New Winds in the Barents Region" sets the framework for cultural cooperation in 2008-2010.

\subsection{Council of the Baltic Sea States (CBSS) ${ }^{4}$}

Meeting in Riga in October 2008, the CBSS Ministers of Culture stressed the importance of culture also as an economic factor in society. They decided to appoint a Senior Officials Group for Culture, due to meet for the first time under the Lithuanian CBSS Presidency in 2009-2010. The Monitoring Group on Cultural Heritage Cooperation was formed in 1998. Areas of cooperation include Underwater Heritage, Coastal Culture and Maritime Heritage, Building Preservation and Maintenance in Practice, and Sustainable Historic Towns.

\subsection{Nordic Council of Ministers (NCM) ${ }^{5}$}

A new structure for cultural cooperation was decided by the Nordic Council of Ministers in 2006. The focus of Nordic cultural co-operation was moved from institutionalised towards thematically defined projects and time-limited programmes. Two such programmes are the Mobility and Residence Programme and the Art and Culture Programme, both recently extended to the end of 2011. Estonia, Latvia and Lithuania joined the mobility program as of 2009. In addition, the Nordic Council of Ministers has a Knowledge Building and Networking Program for cooperation with North West Russia with the aim of enhancing cooperation in different sectors, including culture. In 2007, the Nordic Council of Ministers launched a cross-sectoral three year-initiative, on creative and cultural industries. A working group, KreaNord, was established to coordinate Nordic activities in the realm of creative industries. The Nordic Council of Ministers is an active participant in the implementation of the Northern Dimension Policy and supported in 2007-08 a total of 170 Northern Dimension projects.

\footnotetext{
${ }^{4}$ See appendix 4

${ }^{5}$ See appendix 5
} 


\section{Sources of funding}

The Expert Group notes that there is a great variety of public and private funds, sponsorship possibilities and grants available in the region. A recent survey by the Institute for Russia and Eastern Europe (Helsinki) identified several potential sources of public funding in the ND area for cultural projects. $^{6}$

In this section a brief overview is given of funding available through the European Union and the Nordic Council of Ministers which are the two most important multilateral sources of funding for projects involving more than two countries in the ND area.

The European Union supports cultural cooperation through a variety of instruments, most notably the cultural and audio-visual programmes. EU Member States, as well as Iceland and Norway on the basis of the Agreement on the European Economic Area, are able to participate in the Culture programme (2007-2013) which has a budget of $€ 400$ million for projects and initiatives to celebrate Europe's cultural diversity and enhance the shared cultural heritage through the development of international co-operation between cultural operators and institutions. The Culture programme aims to promote cross-border mobility of those working in the cultural sector; to encourage the transnational circulation of cultural and artistic output and to foster intercultural dialogue.

MEDIA 2007 is the EU support program for the European audiovisual industry. The programme co-finances training initiatives for audiovisual industry professionals, the development of production projects (feature films, television drama, documentaries, animation and new media), as well as the distribution and promotion of European audiovisual works. It also supports pilot projects and a VOD/DCD (Video-on-Demand/Digital Cinema Distribution) scheme to encourage to take-up new technologies by the audiovisual industry. The budget is $€ 755$ million over 7 years (2007-2013). Iceland and Norway are full members of the programme.

The ENPI Institution Building Partnership Programme (IBPP) supports EU-Russia Cultural Cooperation initiatives as part of the EU-Russia Cooperation Programme which is designed to support grass root initiatives in the area of culture. The European Commission promotes activities aimed at boosting cooperation with Russia in the cultural field and promoting innovative artistic and cultural projects with a European dimension. Further financing possibilities are offered by the ENPI Common Space Facility as well as the ENPI Cross-Border Cooperation Programmes.

\footnotetext{
${ }^{6}$ See appendix 6
} 
The Nordic Council of Ministers allocates a significant amount through its annual budget to support art and culture (22.4 Million EUR, 2009). Three programmes, the Art and Culture programme, the NordicBaltic Mobility and Residence Programme and the Computer Game Programme for children and young people, have a total budget of about 5.5 Million EUR. Nordic Council of Ministers main programme for cooperation with Northwest Russia, the Knowledge Building and Network Programme supports Nordic-Russian cooperation in different fields, including culture, with a yearly budget of approximately 2.6 Million EUR.

The Nordic Council of Ministers has two funds that support culture: The Nordic Culture Fund which annually awards approximately 4.5 Million EUR, and the Nordic TV and film funds which allocate approximately 3.3 Million EUR every year.

The Nordic Innovation Centre (NICe), an institution under the Nordic Council Of Ministers, finances projects involving at least three Nordic countries. Efforts are encouraged to engage the Baltic countries and Northwest Russia in the projects. Creative industries are currently one of five focus areas for support. Annual support given by NICe to all types of projects, amounts to more than 5 Million EUR. 


\section{Forums on ND Partnership on Culture}

A Forum was convened by the Nordic Council of Ministers in Helsinki on 11-12 September 2009 to bring together various stakeholders in the region and to provide further expert input to the Expert Group. Its main results are reflected in the chairman's conclusions annexed to this report. ${ }^{7}$

About 160 participants representing cultural practitioners, actors and operators, experts from the Regional Councils and various other organisations active in Northern Europe convened at the forum in Dipoli (Espoo, Finland) and took part in the discussions on the Nordic Councils of Ministers' initiative for the development of creative economy in Northern Europe - KreaNord and on the initiative in the framework of the Northern Dimension policy on examining the desirability of establishing a Northern Dimension Partnership on Culture.

Subject to approval by the Senior Officials Meeting in Stockholm on 12 November, a second ND Partnership Forum with wide participation of cultural stakeholders is envisaged to take place in Saint Petersburg in the spring of 2010.

\footnotetext{
${ }^{7}$ See appendix 7
} 



\section{Some examples of potential projects}

The Nordic Council of Ministers commissioned a consultant to contribute to the planning of the Forum on 11-12 September 2009 and also, based on a dialogue with cultural actors in the Northern Dimension area, to identify potentially relevant projects for an ND Partnership on Culture. A summary of these projects is annexed to this report in order to illustrate the potential of a Northern Dimension Partnership on Culture. ${ }^{8}$

The two projects attached represent two major types of projects; professional networks and professional suppliers of services in creative economy. In the ND area there are a lot of multilateral professional networks working with festivals and other activities with a long-term perspective. These networks and their activities could develop towards "platforms" for creative economy. They need possibilities to plan their activities for several years, to develop their concepts and to be able to work with information, communication and branding. These "platforms" can be very important for artists from ND area as a "show room" or "market place" for their artistic production, for example films, books, visual art, design etc.

The other big group of potential projects consists of services in creative economy. These are often small SMEs which have developed new services based on technology. The project described in the attachment is a new soft ware that makes it possible to reserve and buy tickets to most of the theatres and concert halls in Saint Petersburg. The project offers service in seven languages and it is accessible world wide by mobile phone or internet. The project would make it easier for tourists to visit theatre performances and concerts in Saint Petersburg and would also benefit the tickets sales of theatres and concert halls.

In the group with projects supplying services and contents there are many projects offering experiences connected to cultural heritage and tourism in general.

The projects in the attachment and several other concrete projects were presented and discussed in the Nordic Cultural Forum on Northern Dimension Partnership on Culture in Helsinki 11-12. September 2009.

\footnotetext{
${ }^{8}$ See appendix 8
} 



\section{Recommendations of the Working Group}

\subsection{Desirability of the Partnership}

The Expert Group considers that the NDPC is highly desirable and that it could provide important further impetus to the development of cultural cooperation in the region and beyond. The Expert Group is of the opinion that the Partnership could be an efficient instrument in fostering links between cultural operators and in promoting "links between cultural and economic life" as well as "visibility of regional and local cultural identity and heritage" in line with the Northern Dimension Policy Framework Document.

The Expert Group recommends that a decision to establish the Partnership be taken by the ND Senior Officials at their meeting in Stockholm on 12 November 2009. With a decision on the establishment of the Partnership in place, serious consideration can be given to the kind and extent of resources, both in terms of monetary and various forms of inkind contributions, to be committed in support of the Partnership. The Expert Group encourages all interested parties to explore how they can support the Partnership. The Expert Group expresses its appreciation for support given by the Nordic Council of Ministers and welcomes the willingness indicated by the Nordic Council of Ministers to possibly consider a continuation of its valuable support.

Pending decisions on a Secretariat to the Partnership and other possible resources the Expert Group considers it expedient to distinguish between objectives that can be realised with rather limited resources, e.g. a Secretariat consisting of only one full-time person or less, and objectives that would require significantly more resources.

\subsection{Objectives of the Partnership}

The overall objective of the Partnership is:

To function as a focal point in the field for networks, projects and other cultural activities in the ND area. This includes:

- Providing a platform for exchange of best practices, dialogue and meetings with stakeholders representing government (national, regional and local) and the private sector as well as different sectors of cultural life (state and non-state); 
- Facilitating a dialogue between cultural actors and the business community in order to seek areas of mutually beneficial cooperation and the development of the creative economy;

- Promoting coordination and cooperation between the four Regional Councils in the North with a view to avoiding overlap;

- Providing a point of information allowing relevant actors to keep each other continuously informed of their plans and activities;

- Keeping a comprehensive list of e-mail addresses to relevant actors up-to-date.

A major objective of the Partnership is also:

- To facilitate assessment of the financial viability of projects and access to multiple sources of financing and also to mobilise publicprivate funding for collaborating projects.

Depending on funding possibilities, the Partnership can also set itself more resource demanding objectives, including:

- To arrange for ND cultural products to be presented to international audiences in festivals, exhibitions and similar events;

- To conduct analyses of what different audiences in various countries and regions would like to experience in the ND area;

- To create tools to develop tailor-made cultural tourism in the ND region;

- To promote and organise cultural activities with a focus on people-topeople contacts;

- To encourage capacity-building in the field of marketing and entrepreneurship for artists, cultural institutions and operators.

\subsection{Institutional set-up}

The ad-hoc Expert Group proposes the following two-level institutional structure for the Partnership, composed of the relevant cultural policy and decision makers:

- High Level Meetings to take strategic decisions

- A Steering Group to monitor the implementation of the projects and measures

The Chairmanship will rotate between the Northern Dimension Partners.

The Expert Group expresses its appreciation for the valuable contribution by the Nordic Council of Ministers and considers that the continuation of Nordic Council of Ministers' active support is most welcome. The 
Expert Group proposes that a request be directed to the Nordic Council of Ministers to support the Partnership and the establishment of its Secretariat during 2010 and 2011. The Expert Group is of the opinion that due consideration should be given to the long-term financing needs of the Secretariat at the latest by 2011 .

\subsubsection{High Level Meetings}

The High Level Meetings will give political impetus and strategic orientation and direction to the Partnership. They may take place at the level of Ministers of Culture when necessary and/or when useful deliverables can be put on the table. The High Level Meetings, at the level of Senior Officials, will in any case take place regularly, in principle once a year, to take strategic decisions on the future development and priorities of the Partnership.

\subsubsection{Steering Group}

The Steering Group will monitor the implementation of the Partnership and ensure that the set objectives are met and the agreed projects and measures are carried out as planned. The Steering Group can decide to set up working groups or task forces at expert level involving all or some of the partners. 



\section{Conclusion and summary of the recommendations}

The ad-hoc Expert Group's recommendations are summarised as follows:

- The establishment of a Northern Dimension Partnership on Culture is highly desirable and timely.

- The Partnership should thematically focus on the Northern Dimension region and therefore be open for participation of all ND Partners and other actors in the region. Also Belarus should be invited to participate.

- The overall objective of the Partnership is to function as a focal point for networks, projects and other cultural activities in the ND area.

- As an actively managed point of information, the Partnership will i.a. help promote coordination and cooperation between the four Regional Councils in the North to avoid overlapping and to supplement the efforts of national authorities and also to facilitate a dialogue between cultural actors and the business community in order to seek areas of mutually beneficial cooperation and the development of the creative economy.

- The Partnership will also, as a major objective, facilitate assessment of the financial viability of projects and access to multiple sources of financing and also to mobilise public-private funding for collaborating projects.

- A number of more resource demanding objectives have been identified as also highly desirable provided that required funding possibilities can be secured, including i.e. arranging for ND cultural products to be presented to international audiences in festivals, exhibitions and similar events, conducting analyses of what different audiences in various countries and regions would like to experience in the ND area and measures facilitating the development of tailor-made cultural tourism in the ND region.

- A consultancy study commissioned by the Nordic Council of Ministers to determine the interest of e.g. the film, music, visual arts and tourism businesses in the creation of major cultural projects under the auspices of a Northern Dimension Partnership concluded that the cultural sector with great interest follows the development of the NDPC initiative. The majority of cultural enterprises and projects in the ND region are small and mostly funded by public funds. The NDPC could open up new mechanisms for mixed public- private funding and thus have a positive effect on how the national funding 
and support schemes could develop to meet the challenges the creative economy is facing. In the cultural sector there are also ambitions to develop cultural services for experience tourism and joint sectorspecific initiatives to promote culture and art from the ND region internationally.

- Following the successful Nordic Cultural Forum on Northern Dimension Partnership on culture in Helsinki on 11-12 September 2009, and subject to approval by the upcoming Senior Officials Meeting in Stockholm, a second Nordic Cultural Forum on Northern Dimension Partnership on Culture with wide participation of cultural stakeholders is envisaged to take place in Saint Petersburg in the spring of 2010.

- A two-level structure should be set up consisting of High Level Meetings to take strategic decisions and a Steering Group to monitor implementation of measures and projects. The High Level Meetings, which may take place at the level of Ministers of Culture or at the level of Senior Officials, and the Steering Group should be assisted by a small Secretariat. Support given by the Nordic Council of Ministers has been much appreciated and the Nordic Council of Ministers' willingness to possibly consider a continuation of its valuable support is most welcome.

- The Expert Group encourages all interested parties to explore how they can support the Partnership and its objectives.

- The Partnership should be based on an appropriate legal agreement to be finalised by May 2010, with a view to entering into full operation on 1 January 2011.

- The Expert Group proposes that the work should be continued, under the guidance of the Northern Dimension Steering Group, with a view to finalising the modalities of the Partnership.

Having completed its work, as defined in the terms of reference, the ad hoc Expert Group herewith submits its report to the Northern Dimension Steering Group's consideration in view of the meeting of the Northern Dimension Senior Officials on 12 November 2009. 


\section{Appendices}

\subsection{Appendix 1}

\section{Terms of Reference}

Ad-hoc Expert Group to examine the desirability of a Northern Dimension Partnership on Culture. March 2009

\section{General Scope and Context}

Following its renewal, as decided by the Northern Dimension Summit in November 2006, the Northern Dimension is today a common policy between the EU, Russia, Norway and Iceland. The Summit approved a new Northern Dimension Policy Framework Document and a Political Declaration. In the former the Partners i.a. agreed that research, education and science is one of the priority sectors of the Northern Dimension, including links between cultural and economic life as well as visibility of regional and local cultural identity and heritage. The Framework Document noted that the partners favour the model of Partnerships as an effective way to organise practical implementation of projects in the agreed priority sectors.

In their meeting in St. Petersburg on the 21 November 2007, the Northern Dimension Senior Officials noted the information of the Nordic Council of Ministers on the results of the Conference "Northern Dimension and Culture" (8-9 October 2007, Kajaani, Finland) that showed a considerable potential for the development of the cultural cooperation in the area of the Northern Dimension, and instructed the ND Steering Group to discuss at its nearest meeting together with the Nordic Council Of Ministers the perspectives of such cooperation in the ND framework including the possibility to create a Partnership.

At the first Ministerial meeting of the renewed Northern Dimension in St. Petersburg on 28 October 2008, Ministers emphasized the considerable potential for cultural cooperation in the area of the Northern Dimension. They appreciated the contribution by the Nordic Council of Ministers into the possibility to create a Partnership. They instructed the ND Steering Group to set up an ad-hoc expert group to examine the issue and to assess the feasibility of such a Partnership. The conclusions are to be reported to the next meeting of the ND Senior Officials that will be convened in the second half of 2009. 
In its task, the Expert Group will be inspired by the report of a working group of the Nordic Council of Ministers of Culture on Why establishing a Northern Dimension Partnership on Culture is desirable.

\section{Objective and tasks}

The objective of the Expert Group is to examine the desirability of setting-up a Northern Dimension Partnership on Culture, as requested by the Northern Dimension Ministers. The Group should discuss the general scope and role of the Partnership, its complementarities to the existing formats of cooperation in the ND area, its value added as well as outline the overall targets and practical modalities for the Partnership by taking into consideration existing forms of cultural cooperation among the four Northern Dimension Partners; i.e. it should make recommendations on:

- The geographical scope of the Partnership in line with the Northern Dimension policy objectives.

- The role of the Partnership in the creation and promotion of major cultural projects involving actors in Northern Dimension partner countries wishing to join forces in order to more effectively reach out to an international audience.

- A study should be conducted to determine the interest of e.g. the film, music, visual arts and tourism businesses in the creation and promotion of major cultural projects under the auspices of a Northern Dimension Partnership on Culture.

- How to liaise with the EU-Russia Joint Working Group on Cultural Cooperation and how the Partnership can participate in the implementation of the possible future EU-Russia Culture Action Plan.

- The Partnership's possible role in promoting coordination between the four regional councils in the North to remove overlapping and to supplement the efforts of national authorities.

- Ways and means of organising and financing the Partnership if its desirability is established by the Group.

The Expert Group will associate the existing regional and international organisations and fora in the discussions, when relevant.

The Expert Group may decide to invite independent experts to report on specific issues.

\section{Working methods}

The members of the Expert Group will be experts from the Northern Dimension partner countries: the European Union, Iceland, Norway and the Russian Federation. Belarus may take part as an observer.

The International as well as National Financial Institutions active in the Northern Dimension region, and which contribute to supporting the policy will also be invited to participate in the Working Group. 
The Expert Group will meet three times during spring 2009 or when necessary. The working language will be English.

The Nordic Council of Ministers will provide secretarial and other technical assistance to the Expert Group.

Each party will cover its own costs, including travel and accommodation expenses, incurred in the course of the above mentioned activities.

The Northern Dimension partners will be kept regularly informed of progress. The Expert Group will deliver its report to the ND Steering Group in September 2009.

\subsection{Appendix 2 - Arctic Council (AC)}

Within the Arctic Council, projects relevant to Culture are conducted in the framework of the Sustainable Development Working Group (SDWG). Each project has one or more lead countries and a project team comprised of experts from participating Arctic states, Permanent Participants and Observers. Not all Arctic states and Permanent Participants participate in every project and activity of the SDWG. For copies of reports and more detailed information about a project, please visit the SDWG website: http://portal.sdwg.org.

\section{Culturally-relevant Projects under consideration}

The following projects and activities relating to culture are being actively considered by the SDWG during the coming months.

- Assessment of cultural heritage monuments and sites in the Arctic (Proponent: Norway)

Objectives: Knowledge concerning particularly significant heritage monuments and sites within the Arctic region will be summarized and any gaps in the current knowledge will be identified and filled where possible. International agreement on the irreplaceable heritage values of the identified monuments and sites will be sought through the Arctic Council to recognize the necessity of paying particular attention to the future management of these monuments and sites.

Outreach: Guidelines, or a Statement of Ethical Principles, for the protection and preservation of these designated sites will be presented and an information strategy for international dissemination will be developed for consideration and recommendation by the Arctic Council.

This proposal will be considered at the SDWG Regular Meeting in November 2009.

- Follow-on project to the Arctic Indigenous Languages Symposium (Proponent: Canada) 


\section{Some Recent Culturally-relevant SDWG Projects}

- Arctic Human Development Report (AHDR) (2004) (Lead Country: Iceland)

The AHDR is a comprehensive assessment of human conditions in the entire circumpolar region. Chapter 3 of the report is entitled: Societies and Cultures: Change and Persistence. Copies of the chapters can be obtained from the following web address: http://www.svs.is/AHDR/ AHDR\%20chapters/English\%20version/Chapters\%20PDF.htm

- EALAT: Reindeer herding, traditional knowledge and adaptation to climate change and loss of grazing land (EALAT)(Ongoing) (Lead Country: Norway)

- Arctic Social Indicators (ASI) (2009) (Lead Country: Iceland)

The ASI project is a follow on activity to the Arctic Human Development Report (AHDR). The AHDR does not provide time series data regarding the various elements of human development in the Arctic, nor does it present a suite of quantifiable indicators suitable for use by those seeking to monitor or track changes in human development in the Arctic. The goal of the ASI project is to move toward filling this gap. The development of indicators falls within six domains: (1) Fate control and or the ability to guide one's own destiny; (2) Cultural integrity or belonging to a viable local culture; (3) Contact with nature or interacting closely with the natural world; (4) Material Well-being; (5) Education; (6) Health/ Population.

- Economy of the North (ECONOR 1 \& 2) (2006 and 2009) (Lead Country: Norway)

- ArcticStat (Ongoing) (Lead Country: Canada)

ArcticStat is aimed at responding to the demographic gaps noted in the Arctic Human Development Report (AHDR). The project objective is to centralize relevant Arctic research data as well as facilitate comparative research between circumpolar statistical agencies, databanks and other data sources. (http://www.arcticstat.org). It is anticipated that ArcticStat will play a pivotal role as the SDWG moves toward the development of an integrated SDWG Arctic human development monitoring mechanism.

- Survey of Living Conditions in the Arctic (SLiCA)(Lead Country: Denmark)

SLiCA results are the product of a decade of collaboration among researchers and indigenous peoples. These results take the form of a three- 
part report: (1) Overview; (2) Tables; (3) Questionnaire, which can be accessed at the SLiCA website: http://www.arcticlivingconditions.org.

- Arctic Indigenous Languages Symposium (2009) (Lead Country: Canada)

The Arctic Indigenous Languages Symposium was mandated by the Salekhard Declaration, 2006, which stated that Arctic Council member states and other parties were encouraged to support the cultural diversity of the Arctic and especially uphold and revitalize the indigenous languages; to support the Arctic Indigenous Languages Symposium; and to welcome further projects in this important field. This project was strongly supported by the Permanent Participants and received endorsement as well as approval from both the SDWG and Arctic Ministers respectively.

The underlying objectives of this activity were: to provide an opportunity for the participants to engage policymakers and linguistic experts in discussions on the state of indigenous languages in the Arctic; to consider strategies to help in their revitalization; to build stronger relationships between state governments and indigenous peoples; and to foster a partnership approach toward the revitalization of languages. The Report of the Symposium is a major SDWG deliverable for the 2009 Arctic Council Ministerial Meeting. The full report on the Symposium proceedings, including recommendations, is available on the Arctic Languages website (http://www.arcticlanguages.com). Also included in the report are suggestions on practical actions which the Arctic Council may consider as follow up to this Symposium.

\subsection{Appendix 3 - Barents Euro-Arctic Council (BEAC) (www.beac.st)}

Culture has been an integral part of cooperation in the Barents region ever since the Barents Euro-Arctic Council (BEAC) was set up in 1993. In 2007, a working group at regional level was replaced by a Joint Working Group on Culture under the BEAC and the Barents Regional Council (BRC). Cultural cooperation in 2008-2010 follows the programme New Winds in the Barents Region.

At the International Forum "Culture of the Barents Region" held in Arkhangelsk on 16-18 June 2008, Ministers of Culture and other representatives of BEAC Member States expressed their support for the further development of cultural interaction between the countries in the region and for activities according to the objectives of the New Winds Programme for cultural cooperation in 2008-2010. 


\section{Objectives}

The overall objective of New Winds in the Barents Region is to further strengthen cultural cooperation in the Barents Region. Specifically, the objectives are to promote:

- Cultural diversity and multicultural dialogue, thus increasing tolerance and interaction;

- Culture as a tool for regional, social and economic development;

- The creation of different kinds of new cultural meeting places where people interact, particularly youth.

\section{Cultural diversity and multicultural dialogue}

The Barents region is a unique area in terms of both its history and its culture. It is a region with many cultures and languages. The wealth of the region is its cultural diversity and the cultural cooperation increases mutual understanding and respect.

In order both to increase visibility of culture and cultural heritage of the Barents region and to recognise the contribution of all cultures present in the region it is important to foster cultural diversity in a context of openness and cultural exchange, especially promoting intercultural dialogue and competence, including the promotion of the traditional cultures of the indigenous peoples in the region.

\section{Culture as a tool for regional, social and economic development}

The cultural and creative sectors contribute substantially to regional, social and economic development in the Barents region. It is important to explore and promote the role of culture in supporting and fostering creativity and innovation in the region.

An essential aspect of the cooperation is to increase contacts and develop creative partnerships between the cultural sector and other sectors such as business and industry, research and education. For instance the film industry and tourism represent great potential in the cultural sector. In the constantly growing tourism industry, culture is an increasingly important attraction factor for tourists seeking authenticity and experiences. It is important to develop cultural tourism in ways which ensure that the indigenous and other local cultures are respected.

\section{New cultural meeting places}

People-to-people interaction is an important part of the Barents cooperation. Education, culture, sport, child and youth work and volunteer activities are some of its key components. Cultural activities create meeting places and networks, build trust and often lead to cooperation in other areas.

Ensuring good living conditions for young people in the Barents region is not just a question of providing employment and health services; 
equally vital are good cultural services and opportunities to participate in the development of society. Promoting cultural entrepreneurship among young people and encouraging children and young people to take part in different activities will help to strengthen civil society and democracy in the Barents region.

Due to the fact that the Barents region is a geographically large and sparsely populated area, there is a special need to strengthen cultural cooperation and to create meeting places where cultural actors can convene to develop cooperation projects.

\section{Activities}

The objectives, which will guide the Barents cultural cooperation in the future, will be realized through the following priority activities:

- Networking;

- Capacity building (training programmes for cultural actors in the Barents Region);

- Cooperation and exchange in the fields of arts and culture

- Developing information exchange both internally and externally using of new technology.

- Creating different kinds of new cultural meeting places where people can interact, particularly youth. All activities shall be open for and contain participants of both genders.

\subsection{Appendix 4 - Council of the Baltic Sea States (CBSS) (www.cbss.org)}

Education \& Culture is one of the CBSS five long-term priorities, which in the field of culture may include cultural heritage, contemporary culture and the promotion of regional identity. The CBSS addresses its cultural cooperation through two specialised bodies which report to the Ministers of Culture of the Baltic Sea Region. Conferences of Ministers of Culture have been held on a regular basis since 1993, most recently in Riga in 2008.

\section{Baltic Sea Monitoring Group on Heritage Cooperation (www.baltic-heritage.net)}

Established in 1997, the task of the Monitoring Group is to promote and develop cooperation, mainly between the national bodies responsible for heritage protection, but to also involve other actors, ranging from city planners and museum curators right through to ordinary people.

The four working groups that have been set up cover the fields of (a) Underwater Heritage, (b) Coastal Culture and Maritime Heritage, (c) Building Preservation and Maintenance in Practice, and (d) Sustainable Historic Towns. 
The Monitoring Group has launched several novel initiatives, one of the most widely recognized being the Cultural Heritage Forums, which offer a unique meeting place for professionals working with cultural heritage in the Baltic Sea Region.

The $1^{\text {st }}$ Cultural Heritage Forum, under the heading of Baltic Sea Identity - Common Sea Common Culture?, took place in Gdansk in 2003.

The $2^{\text {nd }}$ Forum, Urban Heritage - Common Privilege, was arranged in Helsinki in 2005.

The $3^{\text {rd }}$ Forum, Cultural Heritage and Tourism Potential, Impact, Partnership and Governance, was hosted in Vilnius in 2007.

The $4^{\text {th }}$ Forum will be arranged in Riga in September 2010 with the theme Cultural Heritage - Contemporary Challenge.

ARS BALTICA (www.ars-baltica.net)

Created in 1991, ARS BALTICA is an international network. It promotes multinational partnership projects involving cooperation between a wide range of institutions and initiatives. Its power and uniqueness lies in combining cultural policy development and close cooperation with cultural operators. Events held under the aegis of ARS BALTICA include i.a.:

- International Contemporary Dance Festivals - the $11^{\text {th }}$ Festival was held in Vilnius in May 2009.

- Biennial of Graphic Art of the Baltic States - the $9^{\text {th }}$ Biennial was staged in Kaliningrad in the fall of 2008.

- Triennial of Photographic Art - the $4^{\text {th }}$ Triennial took place in Kiel, Tallinn, Pori and Berlin in 2007-2008.

- Fredrikstad Animation Festival - this is the oldest animation festival in the Nordic and Baltic Countries. It will next take place in

November 2009.

\subsection{Appendix 5 - Nordic Council of Ministers www.norden.org}

The structure and the working methods for the Nordic cultural cooperation were reformed by the Nordic Council of Ministers in 2006 and the new structure was implemented in 2007. Before 2007 the cooperation was managed by sector and art specific institutions, committees and steering groups. The new structure works with time-limited and thematic programmes which are open for professionals in all fields of culture and art.

The Nordic Council of Ministers allocates a significant amount through its annual budget to support art and culture (22.4 Million EUR, 2009). The three main programmes and the annual funding is allocated through the Art and Culture programme, the Nordic-Baltic Mobility Pro- 
gramme and the Computer Game Programme for children and young people, which all together hold approximately 5.5 Million EUR.

Nordic Council of Ministers has two funds that support culture: The Nordic Culture Fund which annually awards approximately 4.5 Million EUR, and the Nordic TV and film fund which allocate approximately 8 Million EUR every year.

\section{KreaNord}

In 2007, the Nordic Council of Ministers launched a cross-sectoral three year-initiative, on creative and cultural industries. A working group, KreaNord, was established to coordinate Nordic activities in the realm of creative industries. KreaNord shall meet the demand for a joint Nordic development and policy program within the creative industries area. KreaNord acts as a multidisciplinary focus for experiences, knowledge and development visions that cover both business and culture. Its aim is to enhance co-ordination between the Nordic countries, to draw up policy recommendations and to initiate joint-Nordic development and profiling activities. KreaNord has no money to support projects.

\section{Nordic Innovation Centre}

The Nordic Innovation Centre (NICe) is an institution under the Nordic Council of Ministers. It initiates and finances activities that enhance innovation. NICe works primarily with small and medium sized companies in the Nordic region. NICe has prepared a Green Paper on the creative industries which appeared in November 2007. The Green Paper's recommendations constitute a good basis for new Nordic endeavours in this area, to be carried out within the framework of the project "Development and Profiling of the Nordic Region as a centre for creative industries".

\section{Globalization}

The Nordic prime ministers meeting in Punkaharju, Finland, in June 2007 , decided to launch a number of joint globalization initiatives. These initiatives are intended to develop the Nordic welfare model, increase competitiveness through reinforcing co-operation in a number of areas, and to promote the Region as a pioneer in tackling globalization. In the field of culture, the existing initiative deals with the development and profiling of the Nordic Region as a centre for creative industries. The Nordic Councils of Ministers is in the process of initiating new globalisation initiatives in 2010, and one of these will be in the field of "culture and creativity". The Nordic Ministers of Culture have initiated a globalisation strategy for Nordic cultural and media co-operation from 2010.

\section{The Nordic-Baltic Mobility Programmes}

In 2009, the Nordic Council of Ministers together with the Governments of Estonia, Latvia and Lithuania launched three joint Nordic-Baltic mo- 
bility programmes: Public administration, Business and Industry and Culture. The programme for public administration supports exchange and establishment of networks between civil servants in the public sector, including culture. The programme for business and industry promotes economic co-operation, innovation and entrepreneurship to strengthen the global competitive power of the Nordic-Baltic region. The annual budget of each of the two programmes is approximately 270.000 EUR. The Nordic-Baltic Mobility Programme for Culture opens a joint forum for professional artist and culture practitioners in the region. The programme is open for all fields of art and culture and has an annual budget of approximately 1.5. Million EUR.

\section{Knowledge Building and Networking Programme for cooperation}

The Nordic Council of Ministers launched the Knowledge Building and Networking Programme for cooperation with North-West Russia in 2007. The aim of the programme is to build knowledge and promote networking between the Nordic countries and North-West Russia. The programme focuses on exchange of knowledge, experiences and skills as well as establishing networks between partner organization in the Nordic countries and North-West Russia. The programme is designed to serve as seed money to initiate new cooperation activities with the aim of enhancing sustainable and long-term partnerships between North-West Russian and Nordic partner organization.

Through the programme, civil servants, teachers, representatives from small or medium sized enterprises, researchers, politicians, journalists and representatives of NGOs etc. have the opportunity to participate in joint Nordic-Russian exchange activities. Partners for cooperation could be authorities, small or medium sized enterprises, organizations, universities, etc. in the Nordic countries and North-West Russia. The programme is focused so as to support cooperation activities in the following four main areas: Public administration, Research and education, Economic development, Civil society. Cooperation in the field of culture is a priority field under the main area "Civil society". The programme has an annual budget of approximately 2.6 Million EUR.

\section{NGO-program for the Baltic Sea region}

The Nordic Council Of Ministers launched the NGO-programme for the Baltic Sea region in 2006. The programme supports tripartite cooperation between partners from the Nordic countries, Russia or Belarus, Estonia, Latvia, Lithuania or Poland. The aim of the programme is capacity building of NGOs in Russia and Belarus and creation of networks across the Baltic Sea. The programme has an annual budget of approximately 550000 EUR. 


\subsection{Appendix 6 - A mapping of funding channels and cultural projects in the ND-Area}

Report prepared for the Institute for Russia and Eastern Europe, Helsinki By Kira Sjöberg

The aim of this report was to deliver information on funding channels within the Northern Dimension geographical area. The survey was conducted in order to get an idea of what types of projects have been completed and what funding channels exist to support the cultural life in this area. The survey did not further analyse the projects nor funding means and the material is a map of both larger scale projects and smaller scale personal grants and projects.

The information is collected from projects between 2006 and 2008 of most of the funding channels mentioned below. In relation to larger scale international funds, such as Culture 2000, the focus is on the Northern Dimension area. The projects detailed in this report were started and in most cases completed by 2006 .

The material collected is based on internet research in Scandinavian languages, Finnish and English. All amounts are approximate and based on the information published on internet. It is worth noting that the amounts are approximate and only about $70 \%$ of the information could be found with the method used. Time was the main limiting factor in this survey and therefore the focus was primarily on large governmental run funding bodies in the ND area. Secondly some Finnish, sector- specific funding channels were looked at in order to deliver some data from the funding channels in a single country.

The eight multilateral funding channels and the three national Finnish funding schemes were:

- Culture 2000 - Northern Dimension countries ( except Germany)

- Baltic Sea Region Interreg IIIB

- Northern Periphery Programme 2007-2013

- Nordic Cultural Fund

- Nordic Film and TV fund

- Nordic Innovation Centre (NIC)

- Euregio Karelia Neighbourhood Programme

- Ars Baltica

Finland:

- Frame Fund (Finnish Fund for Art Exchange)

- Luses (The Foundation for the Promotion of Finnish Music)

- Esek (The Finnish Performing Music Promotion Centre) 
The three Finnish funding channels are only a few of many national funding channels. If this survey should have looked upon the national funding schemes in the other Nordic and Baltic countries and in Russia the total amount of projects in the ND area during 2006-2008 would have exceeded to several thousands.

\section{Details of the mapping}

The mapping was created based on the criteria of mapping actors applying for funding within the cultural sectors. Seminars and other purely educational projects were not included in this mapping. The lower limit for the funded amount was $€ 4000$. In the national Finnish funding schemes the limit was lowered even further in order to provide as wide as possible a view of potential cultural actors nationally.

The mapping identifies eight main funding channels and includes details of approximately 700 projects funded internationally. Details of grant recipients in Finland add up to approximately the same amount, totally the report has data on 1400 cultural projects $(2006-2008)$. Concerning the Nordic funding the picture may not respond to the normal funding volumes and activities, because the structure of the Nordic cultural cooperation was reformed in 2006 and a new structure with new programs was launched in May 2007. Several pan-Nordic cultural institutions and programs closed down during 2006 and did not grant any funding during the second half of that year. The new programs had their first application dead lines in autumn 2007. This means that the volume of Nordic funding in this report is lower than usual.

Financially the report has a map of $€ 50$ million worth of completed projects $(70 \%$ of estimated sum), which only scratches the surface of all the activity in the cultural field. This report and survey is by no means exhaustive and the material should be further investigated and analysed.

The idea in relation to the selected projects has been the assumption that organisers of these 1400 projects are likely to be active cultural actors, and if presented with a financing mechanism, such as a possible future NDPC, they could have interesting potential projects to suggest for consideration.

\section{Suggestions for future research}

The mapping of this area has showed the great activity on the cultural field, and as stated previously this report only scratches the surface of all available data. Suggestions for further research:

1. A continued mapping of projects in the Northern Dimension area initially mapping out all the international sources, then continuing to national sources including major funds such as the Finnish Cultural Foundation, Swedish Cultural Foundation in Finland and so forth in each member state. 
2. An analysis of the currently mapped out material and the projects' potential to develop towards creative economy if they could work on a long- term funding perspective instead of being funded as one - off projects.

The report and the data will be available at the web site of the Institute of Russia and Eastern Europe, Helsinki in October 2009 www.rusin.fi

\subsection{Appendix 7 - Chair's conclusion}

Northern Dimension Partnership on Culture - Nordic Cultural Forum Creative Economy in Northern Europe

\section{Chair's conclusion}

About 100 participants representing cultural practitioners, actors and operators, experts from the Regional Councils and various other organisations active in Northern Europe convened in Dipoli (Espoo, Finland) on 11 and 12 September 2009 and took part in the discussions on a Northern Dimension Partnership on Culture.

The purpose of the Nordic Cultural Forum on the Northern Dimension Partnership on Culture was to focus on the questions related to creative economy and cultural co-operation in the Northern Dimension region and to examine the feasibility and desirability of establishing a Northern Dimension Partnership on Culture.

The conclusions of the Forum are as follows:

The Forum supported the establishment of the Northern Dimension Partnership on Culture as well as its main objectives as presented by the Chair of the Ad hoc Expert Group, Ms Pia Erson.

The participants of the Forum found it appropriate that the Partnership on Culture should function as a focal point for networks, projects and other cultural activities in the ND region and could facilitate assessments of the financial viability of projects and improve prerequisites for access to multiple sources of financing and also to mobilise public-private funding for cultural projects and enterprises.

The Forum welcomed the cooperation with the Nordic Council of Ministers' initiative KreaNord with the objective to develop cultural cooperation in the field of creative economy and improve competitiveness and welfare of the Northern region as one of the main challenges of globalisation. 
The conclusions of the three workshops are as follows:

1. The first workshop on networks and festivals as platforms for creative economy stated that networks and festivals function as transfer points for new ideas and knowledge. Networks and festivals need international contacts and cooperation, but also collaboration with local and regional networks. Festivals should develop conditions for business and creative economy. The workshop welcomed a Partnership on Culture serving as a focal point, especially from the point of view of facilitating a dialogue between cultural actors and the business com-munity in order to seek areas of mutually beneficial cooperation and the development of the creative economy.

2. The second workshop on developing concepts and services recognised that new technology plays a central role for services in creative economy, both for producers and users. New technology and services can build bridges between various cultural sectors and geographical areas. A possible Partnership on Culture is desirable with a view to conduct analyses of what different audiences in various countries and regions would like to experience in the ND area as well as to encourage capacity-building in the field of marketing and entrepreneurship for artists, cultural institutions and operators.

3. The third workshop on content development as asset for creative enterprises discussed the questions of content managing and intellectual property rights/IPR. The group stated that the main problem is not in content control, but in the control of concepts and brands and in distribution, and more efforts should be made to distribute the products of creative industries. The group also discussed the need for harmonisation in national policy concerning creative economy and hoped that the ND Partnership on Culture could highlight the problems for creative enterprises and thus give new input to national and international efforts to develop the funding instruments to support the creative industry. A Partnership on Culture could open up possibilities to multiple sources of financing and also mobilise public-private funding for cultural projects. The Workshop also considered that a Partnership on Culture could play an essential role in bridging the gap between the different stakeholders. Developing mutual under-standing of the various concepts targeted in the Partnership on Culture is crucial in order to achieve expected results.

Finally, the Nordic Cultural Forum on Northern Dimension Partnership on Culture encourages all interested parties to explore how they can support the Partnership and its objectives. 


\subsection{Appendix 8 - Draft version of two possible projects provided by the consultant}

\section{Tallinn Black Nights Film Festival}

Tallinn Black Nights Film Festival is a feature film festival with the subfestivals of animated films, student films and children/youth films. The festival aims to present to the Estonian audiences a comprehensive selection of world cinema in all its diversity with the emphasis on European films, providing a friendly atmosphere for interaction between the audience, Estonian film makers and their colleagues from abroad.

Tallinn Black Nights Film Festival consists of the main programme, four sub-festivals and a film and co-production market.

The festival screens films from both Western and Eastern Europe is developing its concept towards an important European film festival and market. Film producers in the Nordic and other Baltic Sea countries have growing difficulties getting their films screened at the major European film festivals in Berlin (February), Cannes (May) and Venice (September). The Tallinn Film Festival is in November which gives it a good opportunity to gather film professionals, buyers and media. The festival will have additional programs connected as books and manuscript market for films, seminars and concerts on film music and events that attract others than the film professionals. The festival also plans to develop an internet-based show room for marketing. (Meeting August in Tallinn with Heili Joe, Tallinn film Festival)

Tallinn Film Festival seems to have the potential to develop into a major film festival and market for films produced in the Northern Dimension region. It already works as a "platform" where artists and practitioners get visibility, perform and sell their artistic productions or/and services and connect to culture consumers.

When both the "platform" and the artist/practitioner have an entrepreneurial approach, the platforms as festivals, special thematic weeks etc can be of great value.

Festivals as a way of working are typical in the creative sectors. The festival-format is underestimated by funding bodies and investors, who mostly only look at the incomes collected via tickets. Festivals are also a very efficient tool for the artists to find new engagements and work possibilities. Festivals need to work on long-term bais in order to take a entrepreneurial approach to the creative content.

Internet Booking and Sales of Tickets for Cultural Events in St. Petersburg The service is developed by MIR Services, based in Finland and a Research and Implementation plan is produced by Institute for Cultural Programs, based in St. Petersburg.

All web systems for ticket sales to cultural events, theatre and concerts in St. Petersburg are in Russian and the current Internet- based sales sys- 
tem have call centres and delivery services by courier, which can make the price for the ticket quite high.

The system developed by MIR Services can be used over cell phones and Internet. The system works in 9 languages and the reservation can be charged directly to the buyer's bank account. If the ticket is not charged via the bank within 2 hours from the reservation the reservation will be cancelled. The ticket can be printed or "carried" in the cell phone and then registered at the entrance by an electronic reader.

The system also allows the customer to have a 3D picture of the theatre or concert hall and to choose among available seats for the day of performance.

The study conducted by the Institute for Cultural Programme shows that only $4 \%$ of the St. Petersburg Theatres and Concert Organizations provide tickets booking and selling via own websites.

The Internet Booking system will make the cultural events available for inhabitants in St. Petersburg and for visiting tourists. The reservations and payment can be done 24/7 and worldwide. The system would ease the access to all cultural events in St. Petersburg and thus contributes to the creative economy.

The system has been under development for the last 7 years, partly with support from the Finnish Technology Fund TEKES, but needs still some tuning.

The system can be developed to serve the whole Northern Dimension area. 